\title{
Determinants of migraine headache among regular undergraduate students, of Wollo University, Dessie, Ethiopia: cross- sectional study
}

\author{
Mengesha Birkie ${ }^{1 *}$, Mohammed Endris $^{2}$ and Sintayehu Asnakew ${ }^{3}$
}

\begin{abstract}
Background: The prevalence of migraine headaches varied from 2.4 to $48.5 \%$ worldwide among university students. As per the knowledge of the investigators, the study of migraine headaches is not done in this study area. Hence, this study aimed to assess determinates of migraine headaches among regular undergraduate students, of Wollo University, Dessie, Ethiopia, 2020.

Method: Institution-based cross-sectional study design was conducted from November 15-30/2020 by using a selfadministered questionnaire among 371 regular undergraduate students at Wollo University. A multistage sampling technique was employed to represent our study population. Identity migraine test, Migraine Disability Assessment Questionnaire, perceived stress scale, and Oslo social support scale was used. Descriptive statistics, binary and multiple logistic regression were employed. The adjusted odds ratio at a 95\% confidence interval and level of significance ( $p$-value $<0.05$ ) was used to interpret the findings.

Results: From 371 participants, the prevalence of migraine headache in this study was 34\% (95\% Cl: 29.2, 38.5). Variables statistically associated with migraine headache, were a family history of headache ( $A O R=3.83, \mathrm{Cl}: 2.313$, 6.366), suicidal thoughts in the past 3 months ( $A O R=10.76, \mathrm{Cl}: 2.117,54.74)$, and had low perceived stress $62.6 \%$ $(\mathrm{AOR}=0.374, \mathrm{Cl}: 0.205,0.683)$.

Conclusion: In this study, the prevalence of migraine headaches was very high. Family history of headache, suicidal thoughts, and low perceived stress were determinates for migraine headache. So special emphasis shall be given to those participants who had high perceived stress, a family history of migraine headache, and suicidal thoughts.
\end{abstract}

Keywords: Migraine headache, Wollo University, Students, Ethiopia

\section{Background}

Migraine is an important health problem that affects more than $10 \%$ of the general population [1-3]. However, the prevalence varied from 2.4 to $48.5 \%$ worldwide

\footnotetext{
${ }^{*}$ Correspondence: mengeshasun@gmail.com

${ }^{1}$ Department of Psychiatry, College of Medicine and Health Sciences, Wollo University, Dessie, Ethiopia

Full list of author information is available at the end of the article
}

among university students [4]. Although numerous studies had been conducted on the prevalence of migraine headaches within the general population, there were few studies among university students [5-9].

The prevalence of migraines among medical students ranges from 11 to $40 \%$ worldwide [10-12]. Moreover, migraine is the most common type of headache in young adults [13], and its frequency has been increased during student's educational years of study [14]. The prevalence 
of migraine among university students was in Greece, 2.4\% [15] and in Turkey, 12.4\% [6] in Brazil, 25\% [16], in china 7.91\% [17], in Saudi Arabia 26.3\% [18], in Iran $81.53 \%$ from all types of headache, of the $6.9 \%$ were suffering from migraine headache [19], in Jazan 5\% [20], in Zahedan 7.14\% [21] and Parakou University14.3\% [22].

Several data on the epidemiology of migraines among young people and students are available in western countries [22-25]. Despite, in developing countries in Africa, especially in Ethiopia few data were available. The prevalence of migraine has been estimated to be $19.8 \%$ among Nigerian students [26], in Kenya 33.8\% [27], and in Benin 11.3\% [28]. Moreover, in studies conducted on students at the University of Gondar the prevalence of primary headache was $584(81.11 \%)$, of them, $94(13.06 \%)$ were having a migraine [29].

Factors trigger migraine headaches such as stress, exposure to the sun, sleeplessness, eating habits, changes in weather conditions, temperature, frequent traveling, food items, oral contraceptives, and physical activities. Of them, the most common migraine triggers are lack of sleep and fatigue along with smoking [30-32]. Furthermore, having a family history of migraine, those students who enrolled in the second academic year, fatigue, anxiety, depression, stress, prolonged tension, changes in sleep or lack of sleep, hangovers, medications to treat other disorders, overuse of pain medications, panic attacks, strokes, dehydration, influenza, hypertension, strong odors, allergies, excessive intake of caffeine, caffeine withdrawal, smoked meats, skipping a meal, mechanical factors such as neck strain and cigarette smoking $[18,33]$.

Likewise the study conducted, in Iran University students, stress $63 \%$,sunlight $55.6 \%$,noise $48.1 \%$,fatigue $77.8 \%$,menstruation in women $55.6 \%$,too much work and late sleep at night $40.7 \%$,exercise $(<10 \%)$,smells like cigarette smoke and perfume odor $37 \%$, and some foods like fatty and fried foods 33.3\% [19]. Another study in Zahedan shows that the most common migraine triggers were Stress, 73\% Sleep lack 52.5\%, Reading 39.25\%, and Fasting $39.55 \%$ [21] were the risk factors for migraine headaches.

Migraine headaches hurt individuals' performance, and high costs are imposed on society due to its absenteeism in the workplace as well as education [34-36]. And also migraine headache has impacts on psychological problems such as depression, Obsessive-compulsive disorder, Bipolar and anxiety disorders [37]. Migraine headaches are under-diagnosed and treated conditions in undergraduate students. This leads to the compromised academic performance of students. Based on our knowledge, there are no studies done previously, about migraine headaches among Wollo university students. Therefore, this study aimed to assess the determinates of migraine headaches among regular undergraduate students in Wollo University, Dessie, Ethiopia.

\section{Methods and materials Study design, period, and setting}

An institutional-based cross-sectional study was conducted among regular undergraduate Wollo university students from November 15-30, 2020. Wollo University is one of the thirteen 3rd generation universities which were established in 1997 E.C. It is located in the Amhara region, $401 \mathrm{KM}$ away from the capital city of Ethiopia. The university was starting to work with the enrollment of 749 students in one faculty of education and currently, it has more than 7000 students with six colleges.

\section{Study participants, sample size determination, and sampling technique}

There were a total of 1852 regular undergraduate students registered for the academic year of 2020, across different colleges. The sample size was determined using the single population proportion formula by taking the prevalence of migraine headache 13\% [29], and 95\% confidence interval and, 5\% margin of error was used and finally sample size was 192 . After adding a $5 \%$ none response rate the sample size was 202. Since we were used the multi-stage sampling technique we multiply our sample size by 2 and we got 404. A two-stage cluster sampling technique was employed to select the study participants. In the first stage by using a simple random sampling technique we choose three colleges out of the six colleges. In the second stage, again by applying a simple random sampling technique, we select 6 departments from each chosen college and on the final stage, we proportionally allocated the sample to select 404 participants (Fig. 1). We excluded students with visual impairment, those unable to fill the self-administered questionnaire due to illness, and extension students.

\section{Measurements}

The dependent variable is migraine headache (Yes or No). The independent variable includes socio-demographic characteristics (age, sex, marital status, family history migraine headache, monthly income, living place before joining to campus), academic factors (Academic year, academic CGPA), other potential factors (stress, sunlight, noise, fatigue, heat, menstruation in women, too much work late sleep at night, exercise, smells and some foods) and mental illness-mood and emotional changes, suicidal ideation, and attempt. 


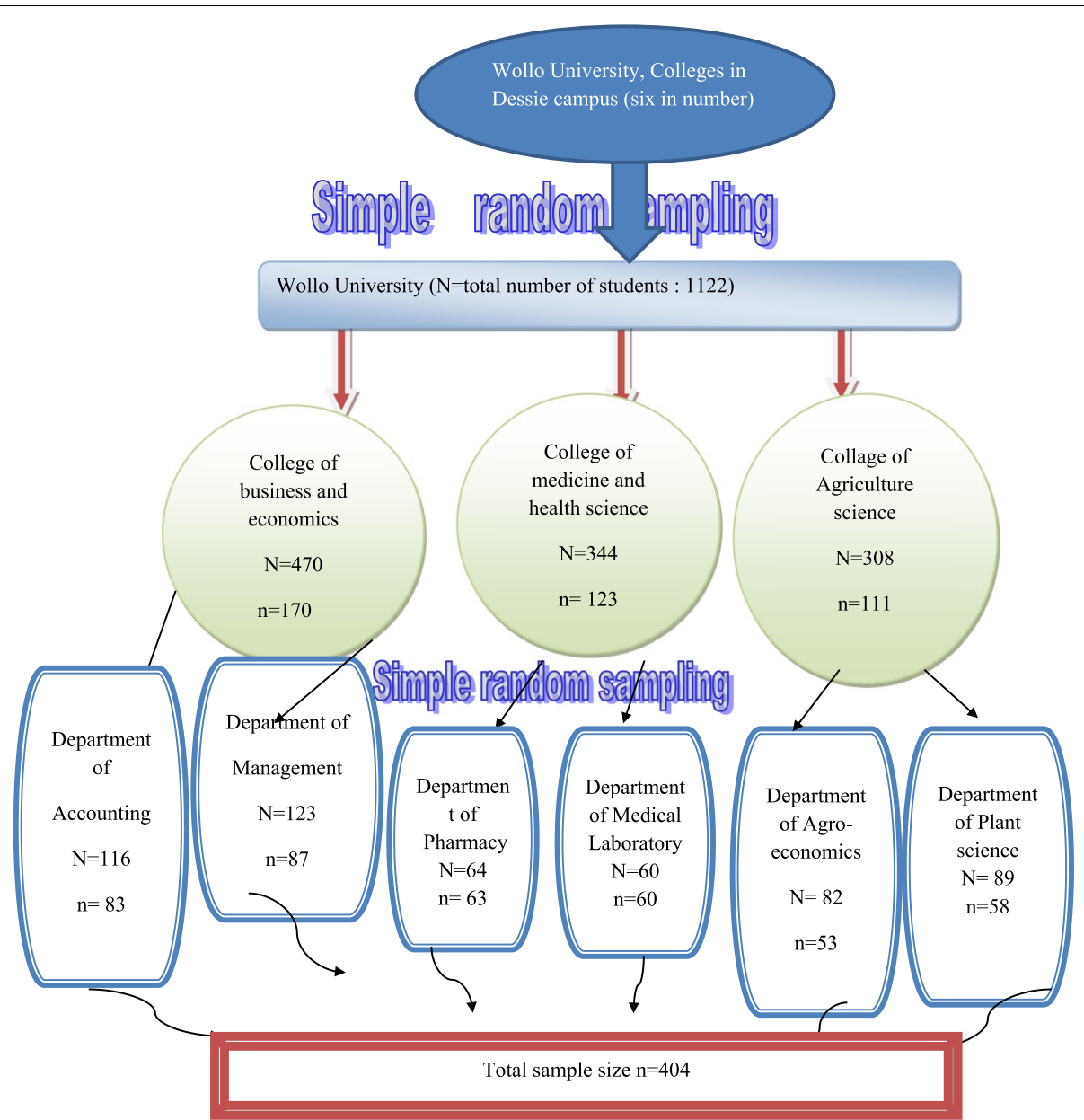

Fig. 1 Schematic presentation of sampling procedure, Wollo University students, Ethiopia Nov 2020

\section{Operational definitions \\ Having migraine headache}

From the Identity migraine test tool used, three questions having one or more symptoms on headacherelated disability, nausea, and photophobia [38].

\section{Migraine disability assessment questionnaire score (MIDAS)}

Score $0-5$ is grade 1 or little or no disability, score $6-10$ is grade 2 or mild disability, score $11-20$ is grade 3 or moderate disability, score 21 and above is the severe disability [39].

Individual scores on the PSS can range from 0 to 40 with higher scores indicating higher perceived stress. Scores ranging from 0 to 13 would be considered low stress, 14-26 would be considered moderate stress and 27-40 would be considered high perceived stress [40].

\section{OSLO social support scale}

A score ranging from 3 to 8 would be considered poor social support, 9-11 moderate social support, and 12-14 strong social support $[41,42]$.

\section{Data collection tools and instrument}

The data was collected using a self-administered questionnaire which contains the socio-demographic variables and different tools were used (Identity migraine test) to measure migraine headache, and its disability (MIDAS), perceived stress (PSS), and level of social support (OSSS-3). Identity migraine testis the most widely used and validated of the migraine tools is the ID Migraine, with three questions on headache-related disability, nausea, and photophobia [38]. MIDAS is used to assign a disability grade indicating the overall intensity of illness during a 3 month recall period: little or no 
disability (grade 1 , score $0-5$ ), mild disability (grade 2 scores 6-10), moderate disability (grade 3, score 11-20), severe disability (grade 4 score 21 and above) [10, 39].

The Perceived Stress Scale (PSS) is a classic stress assessment instrument. The tool, while originally developed in 1983, remains a popular choice for helping us understand how different situations affect our feelings and our perceived stress. The questions in this scale ask about your feelings and thoughts during the last month. In each case, you will be asked to indicate how often you felt or thought a certain way. Which has ten questions, for each question has five alternatives [40]. The OSSS-3 consists of three items assessing the level of social support. It has been recommended for epidemiological and population-based surveys. Consequently, it can be considered a suited instrument for the current thesis $[41,42]$.

\section{Data collection techniques and quality control}

Data were collected by two BSc psychiatry nursing professionals using a self-administered questionnaire having eight parts. The first part is socio-demographic characteristics, the second part is containing questions regarding academic achievement, the third part contains questions used to assess the presence of migraine headache, the fourth part contains questions used to assess migraine disability, the fifth part contains questions related to stress, the sixth part contain factors may intensify migraine headache, the seventh part contains questions related to social support, the eighth part contains questions related to mental health and substance.

We took many measures to assure the quality of data. Before proceeding to data collection the training was given for data collectors about the tools used and how to approach the respondents and to clearly explain the objectives and the purpose of the study. The questionnaire was pre-tested 1 week before the actual data collection time on $5 \%$ of the sample size on undergraduate students at Woldya University and appropriate modification was made. Finally, the questionnaire was written in simple and understandable language, using double data entry, and checked for completeness before data entry and incomplete data was discarded.

\section{Data processing and analysis}

Data clean-up and cross-checking were done before analysis. Data were checked, coded, and entered in EPI data 3.1 version then it was exported to SPSS version 21 for analysis.

Both descriptive and analytical statistical procedures were utilized. Descriptive statistics like percentage mean and standard deviation were used for the presentation of demographic data and prevalence of migraine headache. Tables also were used for data presentation. Binary logistic regression was used to identify factors associated with migraine headaches. Variables with $P$-value of less than 0.25 were considered as a candidate for multivariate analysis. Multiple logistic regression models were fitted to control the possible effect of confounders and finally, the variables which had an independent association with migraine headache were identified based on AOR, with 95\%CI and $p$-value less than 0.05 .

\section{Results}

Socio-demographic characteristics of the respondent

We approached 404 participants, of these 371 respondents participated with a response rate of $91.8 \%$. The mean age of the respondents was 23 years of age with the standard division of \pm 2.836 . More than half of the respondents were male190 (51.2\%), orthodox followers 255 (68.7\%), Amhara by ethnicity 258 (69.5\%), and single 337(90.8\%), while $193(52 \%)$ of them were grown in rural areas. Less than half of the students120(32.3\%) visits a place of worship daily. The average monthly income was 770 ETB and the majority of the students $271(78.3 \%)$ had no family history of migraine headache (Table 1 ).

\section{Academic related characteristics of students}

The majority of the students $233(62.8 \%)$ are in the third year, besides $74(19.9 \%)$ were in the fourth year and the rest $64(17.3 \%)$ are in the fifth year. Besides $78(21 \%)$, 64(17.3\%), and 50(13.5\%) are accounting, pharmacy, and plant science from the selected department respectively. Moreover more than half of 195(52.6\%) students have a cumulative grade point of 3-3.5. (Table 2).

\section{Prevalence of migraine headache among students}

In this study, the lifetime prevalence of migraine headache among regular undergraduate WU students was 34\% (95CI: 29.2, 38.5) (Fig. 2).

\section{Migraine disability assessment, perceived stress, and social support}

Of the total participants, $237(63.9 \%)$ had no disability, $65(17.5 \%)$ had moderate disability, $45(12.1 \%)$ had a mild disability and the rest $24(6.5 \%)$ had severe disability. Similarly out of all participants $226(60.9 \%)$ of the students had moderate perceived stress, $101(27.2 \%)$ had low perceived stress, and 44(11.9\%) had high perceived stress. Among study participants 262(70.62\%) of the students had poor social support, $77(20.75 \%)$ had moderate social support and $32(8.63 \%)$ had strong social support (Figs. 3, 4 and 5).

\section{Factors triggering migraine headache}

The most triggers reported for migraine headache were, noise $225(60.6 \%)$, sunlight 208(56.1\%), fatigue (55.5\%), 
Table 1 Socio-demographic characteristics of regular under graduate WU students, Amhara region, north east Ethiopia, Dessie, November, $2020(n=371)$

\begin{tabular}{|c|c|c|c|}
\hline Character & & Frequency & Percent (\%) \\
\hline \multirow[t]{3}{*}{ Age } & $20-25$ & 334 & 90.0 \\
\hline & $26-30$ & 31 & 8.4 \\
\hline & $>=31$ & 6 & 1.6 \\
\hline \multirow[t]{2}{*}{ Sex } & Male & 190 & 51.2 \\
\hline & Female & 181 & 48.8 \\
\hline \multirow[t]{2}{*}{ Marital status } & Single & 337 & 90.8 \\
\hline & Others & 34 & 9.2 \\
\hline \multirow[t]{3}{*}{ Religion } & Muslim & 100 & 27.0 \\
\hline & Orthodox & 255 & 68.7 \\
\hline & Others & 16 & 4.3 \\
\hline \multirow[t]{4}{*}{ Ethnicity } & Amhara & 258 & 69.5 \\
\hline & Oromo & 55 & 14.8 \\
\hline & Tigre & 41 & 11.1 \\
\hline & others (snnp,benshangul,harer,gam & 17 & 4.6 \\
\hline \multirow[t]{2}{*}{ Family history } & Yes & 99 & 26.7 \\
\hline & No & 272 & 73.3 \\
\hline \multirow[t]{2}{*}{ Living condition } & Urban & 178 & 48.0 \\
\hline & Rural & 193 & 52.0 \\
\hline \multirow[t]{5}{*}{ Frequency of worship } & Daily & 120 & 32.3 \\
\hline & 2-3 times a week & 106 & 28.6 \\
\hline & Weekly & 94 & 25.3 \\
\hline & Less than weekly & 28 & 7.5 \\
\hline & Never & 23 & 6.2 \\
\hline \multirow[t]{4}{*}{ Monthly pocket money } & $0-549$ & 204 & 55.0 \\
\hline & 550-1199 & 130 & 35.0 \\
\hline & 1200-1999 & 17 & 4.6 \\
\hline & $>=2000$ & 20 & 5.4 \\
\hline
\end{tabular}

Table 2 Shows academic-related characteristics of regular undergraduate WU students, Dessie, November, 2020( $n=371)$

\begin{tabular}{llll}
\hline Character & & Frequency & Percentage (\%) \\
\hline Year of study & Third-year & 233 & 62.8 \\
& Fourth-year & 74 & 19.9 \\
& Fifth-year & 64 & 17.3 \\
Students depart- & Pharmacy & 64 & 17.3 \\
ment & Medical laboratory & 57 & 15.4 \\
& Management & 74 & 19.9 \\
& Accounting & 78 & 21.0 \\
& Agro economics & 48 & 12.9 \\
& Plant science & 50 & 13.5 \\
Students CGPA & $3.6-4$ & 46 & 12.4 \\
& $3-3.5$ & 195 & 52.6 \\
& $2.5-2.9$ & 98 & 26.4 \\
& $1-2.4$ & 32 & 8.6 \\
\hline
\end{tabular}

too much work 205(55.3\%), while late sleep at night 182(49.1\%), smell 168(45.3\%), and menstruation of women were $71(19.1 \%)$ (Table 3).

\section{Assessments of substance and mental health}

In our study $15(4 \%)$ of the students had a mental illness, $9(2.4 \%)$ had a history of suicidal attempts, $12(3.2 \%)$ had a suicidal thought in the last 3 months, 59(15.9\%) had substance use (alcohol is the leading $27(7.3 \%)$ ) and 17(4.6\%) had a medical condition (Table 4).

\section{Variables having a $p$-value less than 0.25 in bi-variable analysis}

Variables statistically associated with migraine headache in bivariate analysis ( $p$-value of $<0.25$ ) was female students, marital status of other than single, Muslim in religion, having a family history of headache, never going to place of worship, monthly income of greater than or equal to 2000 , having low perceived stress, and have suicidal thoughts. However, age, ethnicity, 


\section{The prevalence of migrain headache}

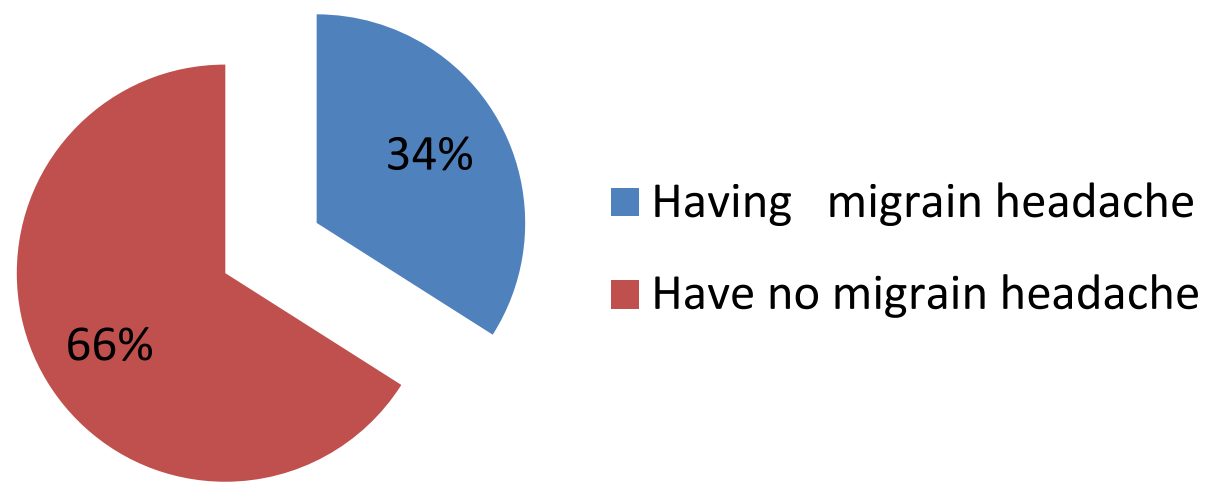

Fig. 2 Prevalence of migraine headache among regular undergraduate WU students, Amhara region, northeast Ethiopia, Dessie, November, 2020(n=371)

\section{The distribussion of migrain headach disability}

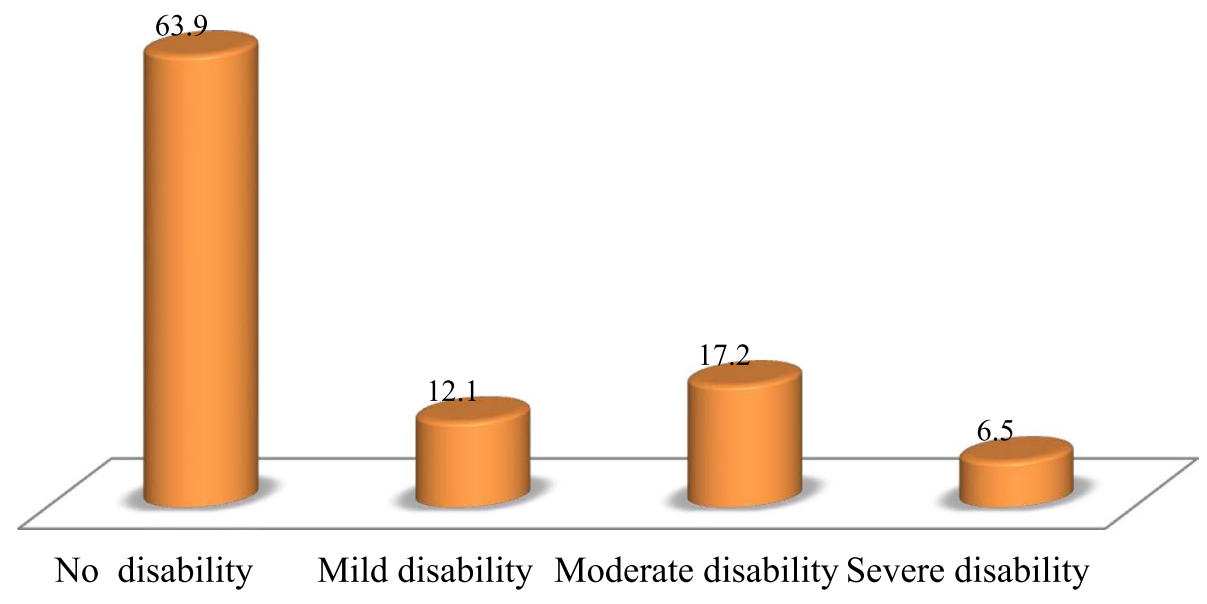

Fig. 3 Assessment of migraine disability among regular undergraduate WU students, Amhara region, northeast Ethiopia, Dessie, November, 2020( $(n=371)$

living residence before campus, study year, social support, and cumulative GPA of the students do not show any association with migraine (Table 5). Those variables with a $P$-value of $<0.25$ in bivariate analysis were entered into multivariable logistic regression for further analysis to control the confounding factors. In multiple logistic regression analysis family history of migraine headache, history of suicidal thought in the past 3 months was significantly associated with migraine headache, while having low perceived stress positively affects the migraine headache.
Factors independently associated with migraine headache On the final model analysis, those who had a family history of headaches are more than 3.83 times $(\mathrm{AOR}=3.83$, CI: $2.313,6.366)$ had a chance of having migraine headaches than those who had no family history of headache. Similarly, those who had suicidal thoughts in the past 3 months are more than 10.76 times $(\mathrm{AOR}=10.76$, CI: $2.117,54.74)$ had a chance of having migraine headaches than, those who had no suicidal thoughts in the past 3 months. But on the other hand, those who had low perceived stress are $62.6 \%(\mathrm{AOR}=0.374, \mathrm{CI}: 0.205,0.683)$ 


\section{The distribution of perceived stress}

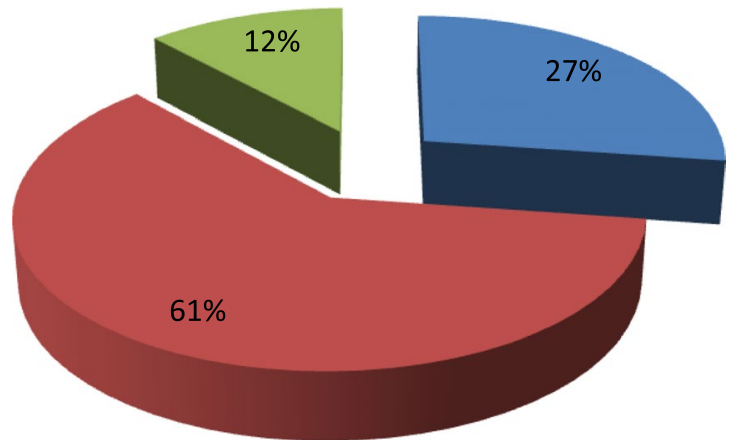

Low perceived stress

Moderate perceived stress

High perceived stress

Fig. 4 Assessment of perceived stress among regular undergraduate WU students, Amhara region, northeast Ethiopia, Dessie, November, 2020 $(n=371)$

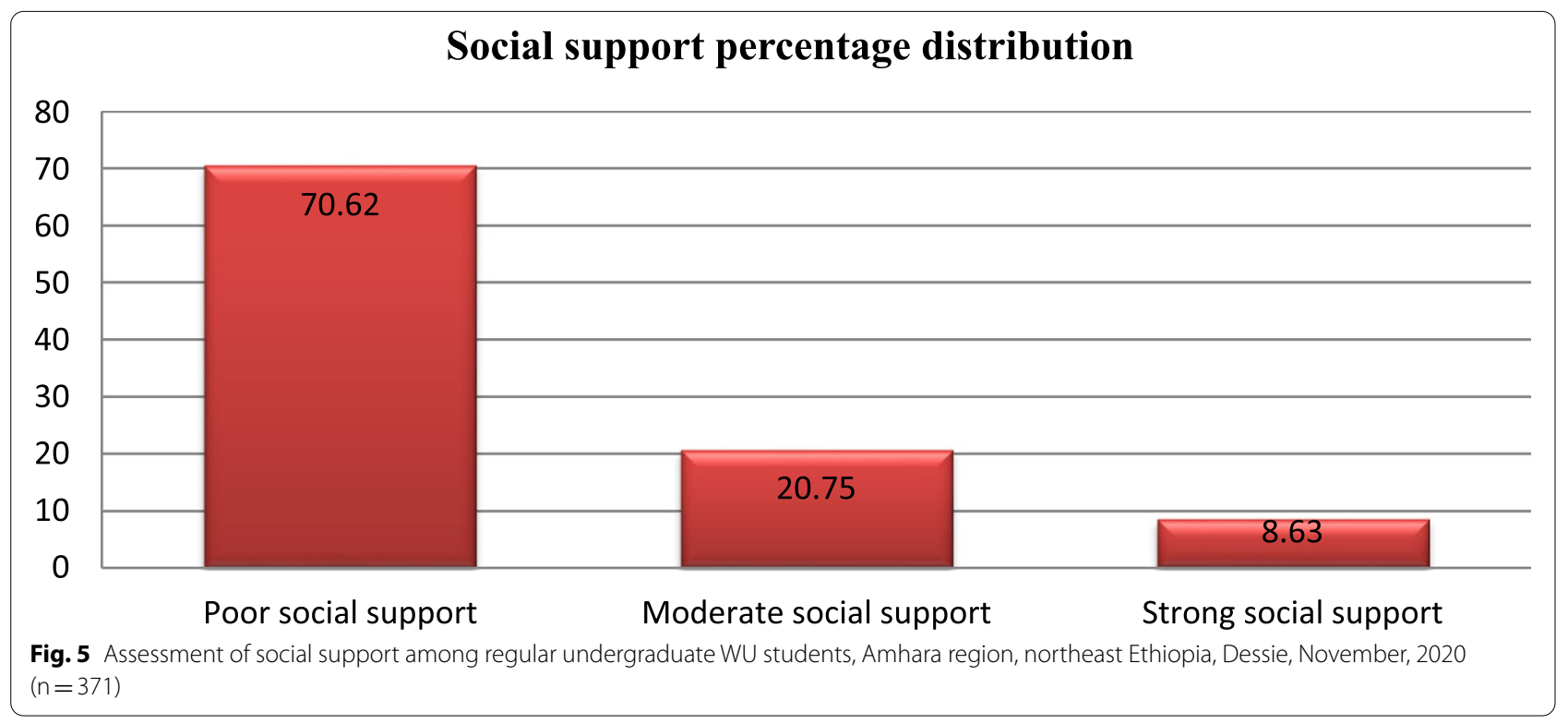

less likely to have migraine headaches than those who had moderate and high perceived stress (Table 6).

\section{Discussion}

In our study, we tried to assess the prevalence, impact, and associated factors of migraine headache among regular undergraduate students in Wollo university. The prevalence of migraine headaches was high. Having a family history of headaches and had suicidal thoughts were the risk factors for migraine headaches, while had low perceived stress was the protective factor.

In our study, the prevalence of migraine headaches among regular graduate Wollo University students was found to be $34 \%$ at $95 \%$ CI $(29.2,38.5)$. This finding is higher as compared with the study conducted in Gondar university $13.06 \%[29,43]$. This may be due to different stressors like covid-19 epidemics during the data were collected. Likewise, in the study conducted inParakou Beninethe, lifetime prevalence was $14.3 \%$ (95\% CI 12.3 to $16.4 \%$ ) [22], in Zahedan among medical students was $7.14 \%$ [21, 42], in Greece, was 2.4\% [18], and in Turkey was $12.4 \%$ [10]. This difference might be due to time variation, cultural and geographical differences, and environmental factors.

In our study the prevalence was slightly higher than the study conducted in Nigeria among nursing students was 26.8\% [37], in Brazil, found a prevalence of $25 \%$ of migraines [10], and in King Abdul-Aziz University was $26.3 \%$ [37]. This might be due to sampling 
Table 3 Potential aggravating factors of migraine headache, among regular undergraduate WU students, Dessie,November, 2020 $(n=371)$

\begin{tabular}{|c|c|c|c|}
\hline Character & & Frequency & Percentage (\%) \\
\hline \multirow[t]{2}{*}{ Headache aggravated by exercise } & Yes & 133 & 35.8 \\
\hline & No & 238 & 64.2 \\
\hline \multirow[t]{2}{*}{ Headache aggravated by sunlight } & Yes & 208 & 56.1 \\
\hline & No & 163 & 43.9 \\
\hline \multirow[t]{2}{*}{ Headache aggravated by fatigue } & Yes & 206 & 55.5 \\
\hline & No & 165 & 44.5 \\
\hline \multirow[t]{2}{*}{ Headache aggravated by too much work } & Yes & 205 & 55.3 \\
\hline & No & 166 & 44.7 \\
\hline \multirow[t]{2}{*}{ Headache aggravated by noise } & Yes & 225 & 60.6 \\
\hline & No & 146 & 39.4 \\
\hline \multirow[t]{2}{*}{ Headache aggravated by menstruation (women) } & Yes & 71 & 19.1 \\
\hline & No & 110 & 29.6 \\
\hline \multirow[t]{2}{*}{ Headache aggravated by late sleep at night } & Yes & 182 & 49.1 \\
\hline & No & 189 & 50.9 \\
\hline \multirow[t]{2}{*}{ Headache aggravated by smells } & Yes & 168 & 45.3 \\
\hline & No & 203 & 54.7 \\
\hline \multirow[t]{2}{*}{ Headache aggravated by food } & Yes & 79 & 21.3 \\
\hline & No & 292 & 78.7 \\
\hline
\end{tabular}

Table 4 Assessments of substance and mental health among regular undergraduate WU students, Dessie, Amhara region, northeast Ethiopia, November $2020(n=371)$

\begin{tabular}{|c|c|c|c|c|}
\hline \multicolumn{3}{|l|}{ Character } & \multirow{2}{*}{$\begin{array}{l}\text { Frequency } \\
15\end{array}$} & \multirow{2}{*}{$\begin{array}{l}\text { Percentage (\%) } \\
4.0\end{array}$} \\
\hline History of mental illness & Yes & & & \\
\hline & No & & 356 & 96.0 \\
\hline \multirow[t]{2}{*}{ History of suicidal attempt } & Yes & & 9 & 2.4 \\
\hline & No & & 362 & 97.6 \\
\hline \multirow[t]{2}{*}{ Suicidal thoughts in the last 3 month } & Yes & & 12 & 3.2 \\
\hline & No & & 359 & 96.8 \\
\hline \multirow[t]{8}{*}{ Substance use history } & Yes & Alcohol & 27 & 7.3 \\
\hline & & Khat & 20 & 5.4 \\
\hline & & Cigarettes & 2 & 0.5 \\
\hline & & Hashish & 2 & 0.5 \\
\hline & & Shisha & 1 & 0.3 \\
\hline & & Cannabis & 2 & 0.5 \\
\hline & & Others & 5 & 1.3 \\
\hline & No & & 312 & 84.1 \\
\hline \multirow[t]{5}{*}{ Diagnosed medical illness } & Yes & HTN & 1 & 0.3 \\
\hline & & $\mathrm{DM}$ & 0 & 0.0 \\
\hline & & Epilepsy & 5 & 1.3 \\
\hline & & Others & 11 & 3 \\
\hline & No & & 354 & 95.4 \\
\hline
\end{tabular}

size differences, cultural and geographical differences, and environmental factors. However, our finding is in line with the study conducted in Kenya 33.8\% [13]. In our study the MIDAS showed that 237(63.9\%) had no disability (grade I), 65(17.5\%) had a moderate disability (grade III), 45(12.1\%) had a mild disability (grade II) and the rest $24(6.5 \%)$ had a severe disability (grade IV). This is consistent with an epidemiological study conducted 
Table 5 Bivariate analysis: Comparison of socio-demographic characteristics, social support, and perceived stress among regular undergraduate WU students, Dessie, November, 2020(n=371)

\begin{tabular}{|c|c|c|c|c|c|}
\hline \multirow[t]{2}{*}{ Character } & & \multicolumn{2}{|c|}{ Migraine headache } & \multirow[t]{2}{*}{$\operatorname{COR}(95 \% \mathrm{Cl})$} & \multirow[t]{2}{*}{$P$-value } \\
\hline & & Yes & No & & \\
\hline \multirow[t]{3}{*}{ Age } & $20-25$ & 115(31\%) & 219(59\%) & Reference & \\
\hline & $26-30$ & $10(2.7 \%)$ & $21(5.7 \%)$ & $.38(0.044,3.299)$ & 0.381 \\
\hline & $>=31$ & $1(.3 \%)$ & $5(1.3 \%)$ & $.42(0.043,4.087)$ & 0.455 \\
\hline \multirow[t]{2}{*}{ Sex } & Male & $71(19.1 \%)$ & 119(32.1\%) & Reference & \\
\hline & Female & $55(14.8 \%)$ & $126(34 \%)$ & $.73(0.475,1.127)^{\mathrm{a}}$ & 0.156 \\
\hline \multirow[t]{2}{*}{ Marital status } & Single & $118(31.8 \%)$ & 219(59\%) & Reference & \\
\hline & Others & $8(2.2 \%)$ & $26(7 \%)$ & $.57(0.25,1.3)^{\mathrm{a}}$ & 0.18 \\
\hline \multirow[t]{3}{*}{ Religion } & Muslim & $41(11.1 \%)$ & $59(15.9 \%)$ & $.68(.423,1.09)^{\mathrm{a}}$ & 0.116 \\
\hline & Orthodox & $82(22.1 \%)$ & $173(46.6 \%)$ & Reference & \\
\hline & Others & $3(.8 \%)$ & $13(3.5 \%)$ & $2.05(0.57,7.4)$ & 0.27 \\
\hline \multirow[t]{4}{*}{ Ethnicity } & Amhara & $91(24.5 \%)$ & $167(45 \%)$ & Reference & \\
\hline & Oromo & $17(4.6 \%)$ & $38(10.2 \%)$ & $1.28(0.473,3.489)$ & 0.623 \\
\hline & Tigre & $11(3 \%)$ & $30(8.1 \%)$ & $1.565(0.509,4.808)$ & 0.43 \\
\hline & Others & $7(1.9 \%)$ & $10(2.7 \%)$ & $1.9(0.582,6.26)$ & 0.286 \\
\hline \multirow[t]{2}{*}{ Family history of headache } & Yes & $57(15.4 \%)$ & $42(11.3 \%)$ & $0.25(0.157,0.406)^{a}$ & 0.00 \\
\hline & No & $69(18.6 \%)$ & $203(54.7 \%)$ & Reference & \\
\hline \multirow[t]{2}{*}{ Living residence } & Urban & $63(17 \%)$ & $115(31 \%)$ & $0.885(0.575,1.36)$ & 0.576 \\
\hline & Rural & $63(17 \%)$ & $130(35 \%)$ & Reference & \\
\hline \multirow[t]{5}{*}{ Frequency of worship } & Daily & $39(10.5 \%)$ & $81(21.8 \%)$ & Reference & \\
\hline & 2-3timesaweek & $36(9.7 \%)$ & $70(18.9 \%)$ & $0.733(0.268,2.005)$ & 0.545 \\
\hline & Weekly & $31(8.4 \%)$ & $63(17 \%)$ & $0.686(0.249,1.89)$ & 0.467 \\
\hline & Less than weekly & $14(3.8 \%)$ & $14(3.8 \%)$ & $0.717(0.257,2.00)$ & 0.525 \\
\hline & Never & $6(1.6 \%)$ & $17(4.6 \%)$ & $0.353(0.107,1.16)^{a}$ & 0.086 \\
\hline \multirow[t]{4}{*}{ Monthly income } & $0-549$ & $73(19.6 \%)$ & $131(35.3 \%)$ & Reference & \\
\hline & $550-1199$ & $40(10.8 \%)$ & $90(24.3 \%)$ & $0.598(0.209,1.712)$ & 0.338 \\
\hline & 1200-1999 & $8(2.2 \%)$ & $9(2.4 \%)$ & $0.75(0.255,2.2050$ & 0.601 \\
\hline & $>=2000$ & $5(1.4 \%)$ & $15(4 \%)$ & $0.375(0.093,1.505)^{a}$ & 0.167 \\
\hline \multirow[t]{3}{*}{ Study year } & Third-year & $76(20.5 \%)$ & $157(42.3 \%)$ & Reference & \\
\hline & Fourth-year & $25(6.7 \%)$ & $49(13.2 \%)$ & $1.324(0.747,2.346)$ & 0.336 \\
\hline & Fifth year & $25(6.7 \%)$ & $39(10.5 \%)$ & $1.256(0.627,2.52)$ & 0.52 \\
\hline \multirow[t]{4}{*}{ Cumulative GPA } & $3.6-4$ & $18(5 \%)$ & $28(7.5 \%)$ & $0.814(0.42,1.578)$ & 0.543 \\
\hline & $3-3.5$ & $67(18 \%)$ & $128(34.5 \%)$ & Reference & \\
\hline & $2.5-2.9$ & $32(8.6 \%)$ & $66(18 \%)$ & $1.08(0.645,1.807)$ & 0.771 \\
\hline & $1-2.4$ & $9(2.4 \%)$ & $23(6 \%)$ & $1.221(0.53,2.815)$ & 0.639 \\
\hline \multirow[t]{2}{*}{ Mental illness } & Yes & $11(3 \%)$ & $4(1 \%)$ & $1.74(0.054,0.557)^{\mathrm{a}}$ & 0.003 \\
\hline & No & $115(31 \%)$ & $241(65 \%)$ & Reference & \\
\hline \multirow[t]{3}{*}{ Perceived stress } & Low & $18(4.7 \%)$ & $83(22.4 \%)$ & $3.166(1.782,5.624)^{\mathrm{a}}$ & 0.00 \\
\hline & Moderate & $92(25 \%)$ & 134(36.1\%) & Reference & \\
\hline & High & $16(4.3 \%)$ & $28(7.5 \%)$ & $1.201(0.615,2.346)$ & 0.591 \\
\hline \multirow[t]{3}{*}{ Social support } & Poor & $89(24 \%)$ & $173(46.6 \%)$ & Reference & \\
\hline & Moderate & $24(6.5 \%)$ & $53(14.3 \%)$ & $1.33(0.628,2.817)$ & 0.456 \\
\hline & Strong & $13(3.5 \%)$ & $19(5.1 \%)$ & $1.511(0.643,3.551)$ & 0.344 \\
\hline \multirow[t]{2}{*}{ Have you ever attempt suicide } & Yes & $7(1.9 \%)$ & $2(0.5 \%)$ & $0.14(0.029,0.684)^{a}$ & 0.015 \\
\hline & No & $116(31.3 \%)$ & $243(0.5 \%)$ & Reference & \\
\hline \multirow{2}{*}{$\begin{array}{l}\text { In the last } 3 \text { month do you have sui- } \\
\text { cidal thought }\end{array}$} & Yes & $10(2.7 \%)$ & $2(0.5 \%)$ & $0.095(0.021,0.443)^{\mathrm{a}}$ & 0.03 \\
\hline & No & $116(31.3 \%)$ & $243(0.5 \%)$ & Reference & \\
\hline
\end{tabular}

${ }^{a}$ Variable shows statistical significance associated with migraine headache on bivariate analysis 
Table 6 Multiple logistic regressions: factors independently associated with migraine headache among regular undergraduate WU students, Dessie, November, 2020( $n=371)$

\begin{tabular}{|c|c|c|c|c|}
\hline Character & & COR & AOR & $P$-value \\
\hline \multirow[t]{2}{*}{ Sex } & Male & Reference & Reference & \\
\hline & Female & $0.73(0.475,1.127)$ & $1.135(0.69,1.855)$ & 0.614 \\
\hline \multirow[t]{2}{*}{ Marital status } & Single & Reference & Reference & \\
\hline & Others & $0.57(0.25,1.3)$ & $2.714(0.981,7.504)$ & 0.054 \\
\hline \multirow[t]{3}{*}{ Religion } & Muslim & $0.68(.423,1.09)$ & $0.667(0.386,1.153)$ & 0.147 \\
\hline & Orthodox & Reference & Reference & \\
\hline & Others & $2.05(0.57,7.4)$ & $1.66(0.42,6.58)$ & 0.469 \\
\hline \multirow[t]{2}{*}{ Family History of headache } & Yes & $0.25(0.157,0.406)$ & $3.837(2.313,6.366)^{a}$ & 0.00 \\
\hline & No & Reference & Reference & \\
\hline \multirow[t]{5}{*}{ Frequency of worship } & Daily & Reference & Reference & \\
\hline & 2-3timesaweek & $0.733(0.268,2.005)$ & $0.952(0.511,1.772)$ & 0.876 \\
\hline & Weekly & $0.686(0.249,1.89)$ & $0.917(0.477,1.766)$ & 0.797 \\
\hline & Less than weekly & $0.717(0.257,2.00)$ & $0.445(0.173,1.14)$ & 0.092 \\
\hline & Never & $0.353(0.107,1.16)$ & $2.15(0.677,6.852)$ & 0.194 \\
\hline \multirow[t]{4}{*}{ Monthly income } & $0-549$ & Reference & Reference & \\
\hline & $550-1199$ & $0.598(0.209,1.712)$ & $1.333(0.784,2.269)$ & 0.289 \\
\hline & 1200-1999 & $0.75(0.255,2.2050$ & $0.697(0.216,2.25)$ & 0.546 \\
\hline & $>=2000$ & $0.375(0.093,1.505)$ & $1.138(0.338,3.835)$ & 0.835 \\
\hline \multirow[t]{3}{*}{ Perceived stress } & Low & $3.166(1.782,5.624)$ & $0.374(0.205,0.683)^{a}$ & 0.001 \\
\hline & Moderate & Reference & Reference & \\
\hline & High & $1.201(0.615,2.346)$ & $0.468(0.2,1.095)$ & 0.08 \\
\hline \multirow[t]{2}{*}{ Mental illness } & Yes & $1.74(0.054,0.557)$ & $3.055(0.602,15.5)$ & 0.178 \\
\hline & No & Reference & Reference & \\
\hline \multirow[t]{2}{*}{ Have you ever attempt suicide } & Yes & $0.14(0.029,0.684)$ & $0.635(0.026,15.29)$ & 0.78 \\
\hline & No & Reference & Reference & \\
\hline \multirow{2}{*}{$\begin{array}{l}\text { In the last } 3 \text { month do you have suicidal } \\
\text { thought }\end{array}$} & Yes & $0.095(0.021,0.443)$ & $10.76(2.117,54.74)^{\mathrm{a}}$ & 0.004 \\
\hline & No & Reference & Reference & \\
\hline
\end{tabular}

${ }^{a}$ Variables shown statistical significance associated with migraine headache on adjusted odds ratio

in France, distribution of the MIDAS grade was found to be $74.7 \%$ grade I, $13.3 \%$ grade II, $7.7 \%$ grade III, and $4.3 \%$ grade IV [44].

In this study among the factors affecting the intensification of migraine headache, noise (60.6\%), sunlight (56.1\%), fatigue $(55.5 \%)$, too much work $(55.3 \%)$, late sleep at night (49.1\%), smell (45.3\%), exercise (35.8\%), foods $(21.3 \%)$ and in women menstruation $(19.1 \%)$. For instance on the study conducted on Iran medical students the factors that had the highest effect on the intensification of migraine were fatigue (77.8\%), stress $(63 \%)$,sun light (55.6\%),noise (48.1\%), menstruation in women $(55.6 \%)$, late sleep at night $(40.7 \%)$,exercise $(<10 \%)$,smells like cigarette smoke and perfume odor (37\%), and some foods like fatty (33.3\%) [12].

Based on our study one of the factors that strongly associate with migraine is had a family history of headaches which increased the risk of migraine more than 3.83 times ( $\mathrm{AOR}=3.83,95 \% \mathrm{CI}: 2.313,6.366)$ than those who had no family history of migraine headache. This is consistent with a study conducted at King Abdul-Aziz University [37]. But our finding is lower as compared with the study conducted in southeast China [10].

Moreover, in this study those who had suicidal thoughts in the past 3 months are more than 10.76 times $(\mathrm{AOR}=10.76,95 \% \mathrm{CI}: 2.117,54.74)$ had a chance of having migraine headache than those who had no suicidal thoughts in the past 3 months. Our finding was supported by the studies done in Taiwan [7]. However, our finding is somewhat high as compared with the study conducted in Rom [12]. This difference may be due to using a different type of method and geographical variation.

In this study having low perceived stress $61.4 \%$ $(\mathrm{AOR}=0.386,95 \% \mathrm{CI}: 0.207,0.72)$ were less likely to had migraines than those who had moderate and high perceived stress. This is consistent with the study conducted on Jazan medical students [20]. Besides in our study, we observed no relation to gender as in the study done in 
Iran-Zahedan, but there was a female predominance in most of the other studies in Riyadh, [36] in the USA, [12] in Nigeria, Brazil, and Turkey [9]. This difference may be due to using a different type of method, geographical variation, and cultural differences.

\section{Conclusion and recommendations}

This study was aimed to assess the determinates of migraine headaches among regular undergraduate Wollo University students. Therefore the prevalence of migraine headaches was found to be very high. The predictors of migraine headaches were a family history of headaches, suicidal thoughts in the past 3 months, and had low perceived stress. So we recommend for different stakeholders, attention shall be given to those study participants who had a family history of migraine headache, suicidal thoughts, and high perceived stress.

\section{Strength and limitations}

Conducting this study is important because as university students the curriculum requires constant concentration and hard work, students even a one-day absence of student can affect his/her school success, so we think that our research is important as it confirms the opportunity to evaluate migraine prevalence and its determinates, in a population where the disease could exert a relevant negative impact. The use of validated tools, doing multivariate logistic regression for analysis of data to control possible confounders could be our strength.

Besides this study had some limitations, which include using the cross-sectional method does not show cause and effect relationship. And also suicidal ideation and suicide attempts were evaluated using yes or no questionnaires rather than through psychiatric standardized evaluation tools. Furthermore, we did not classify migraine headaches, with aura and without aura. Therefore, we recommend further studies employing using psychiatric standardized evaluation tools to clarify suicide risk among patients with migraine headaches.

\section{Abbreviations \\ AOR: Adjusted Odd Ratio; CBE: Community Based Education; CGPA: Cumula- tive; ETTH: Episodic Tension-Type Headache; ETB: Ethiopian Birr; MIDAS: Migraine Disability Assessment score; HRQoL: Health-Related Quality of Life; ID Migraine: Identity migraine; SPSS: Statistical Package for Social Science; WU: Wollo University; WHO: World Health Organization.}

\section{Acknowledgments}

We acknowledge the data collectors for their efforts to collect data and study participants for their involvement in this study.

\section{Methods and procedure}

The method was done based on the guild line of research protocol prepared by the University of Wollo and following all the procedures accordingly, which helps us to show the result of this study by publishing it in a scientific journal.

\section{Authors' contributions}

$\mathrm{MB}$ and $\mathrm{ME}$ contributed to conceptualizing the design, conduct, doing the analysis, write up, and interpreted the outcome of the analysis and manuscript preparation. SA participated in the editing of the manuscript. All authors read and proved the manuscript.

Funding

The researchers have no funding to report for publication fee.

\section{Availability of data and materials}

The authors approved that the data supporting the conclusions of this article will be made available with the hand of Mengesha Birkie by (Email: menge shasun@gmail.com) as per requested.

\section{Declarations}

Ethics approval and consent to participate

Ethical approval was approved from Wollo University College of medicine and the health sciences department of the psychiatry ethical committee. The participants provided their written informed consent to participate in this study and for severe disability participants from their guardians and all methods were carried out in accordance with relevant guidelines and regulations.

\section{Consent for publication}

Not applicable.

\section{Competing interests}

The authors declare that they have no conflict of interests.

\section{Author details}

${ }^{1}$ Department of Psychiatry, College of Medicine and Health Sciences, Wollo University, Dessie, Ethiopia. ${ }^{2}$ Department of psychiatry, College of Medicine and Health Sciences, Wollo University, Dessie, Ethiopia. ${ }^{3}$ Department of Psychiatry, School Of Medicine, College Of Health Science Debre Tabor University, Debre Tabor, Ethiopia.

Received: 17 July 2021 Accepted: 21 October 2021

Published online: 10 November 2021

\section{References}

1. Robbins MS, Lipton RB. The epidemiology of primary headache disorders. In: Seminars in neurology: @ Thieme Medical Publishers; 2010.

2. Rasmussen BK, Jensen R, Schroll M, Olesen J. Epidemiology of headache in a general population — a prevalence study. J Clin Epidemiol. 1991:44(11):1147-57.

3. Özge A, Bugdayci R, Sasmaz T, Kaleagasi H, Kurt Ö, Karakelle A, et al. The sensitivity and specificity of the case definition criteria in Mersin. CephalaIgia. 2002;22(10):791-8.

4. Wang $X$, Zhou H, Sun J, Xing Y, Zhu Y, Zhao Y. The prevalence of migraine in university students: a systematic review and meta-analysis. Eur J Neurol. 2016;23(3):464-75.

5. Bicakci S, Bozdemir N, Over F, Saatci E, Sarica Y. Prevalence of migraine diagnosis using ID migraine among university students in southern Turkey. J Headache Pain. 2008;9(3):159-63.

6. Demirkirkan MK, Ellidokuz H, Boluk A. Prevalence and clinical characteristics of migraine in university students in Turkey. Tohoku J Exp Med. 2006;208(1):87-92.

7. Bicakci S, Over F, Aslan K, Bozdemir N, Saatci E, Sarica Y. Headache characteristics in senior medical students in Turkey. Tohoku J Exp Med. 2007:213(3):277-82

8. Ojini F, Okubadejo N, Danesi M. Prevalence and clinical characteristics of headache in medical students of the University of Lagos, Nigeria. Cephalalgia. 2009;29(4):472-7. 
9. Deleu D, Khan M, Humaidan H, Al Mantheri Z, Al Hashami S. Prevalence and clinical characteristics of headache in medical students in Oman. Headache: J Head Face Pain. 2001;41 (8):798-804.

10. Adoukonou T, Houinato D, Kankouan J, Makoutode M, Paraiso M, Tehindrazanarivelo A, et al. Migraine among university students in Cotonou (Benin). Headache: J Head Face Pain. 2009;49(6):887-93.

11. Ferri-de-Barros JE. Alencar MJd, Berchielli LF, Castelhano junior LC. Headache among medical and psychology students. Arq Neuropsiquiatr. 2011:69(3):502-8.

12. Amayo E, Jowi J, Njeru E. Headache associated disability in medical students at the Kenyatta National Hospital, Nairobi. East Afr Med J. 2002;79(10):519-23.

13. Balaban H, Semiz M, Şentürk IA, Kavakçı Ö, Cınar Z, Dikici A, et al. Migraine prevalence, alexithymia, and post-traumatic stress disorder among medical students in Turkey. J Headache Pain. 2012;13(6):459-67.

14. Galinović I, Vuković V, Trošelj M, Antić S, Demarin V. Migraine and tensiontype headache in medical students: a questionnaire study. Collegium Antropologicum. 2009;33(1):169-73.

15. Mitsikostas D, Gatzonis S, Thomas A, Kalfakis N, Llias A, Papageoergiou C. An epidemiological study of headaches among medical students in Athens. Headache: J Head Face Pain. 1996;36(9):561-4.

16. Bigal ME, Bigal JM, Betti M, Bordini CA, Speciali JG. Evaluation of the impact of migraine and episodic tension-type headache on the quality of life and performance of a university student population. Headache: J Head Face Pain. 2001;41(7):710-9.

17. Gu X, Xie Y. Migraine attacks among medical students in Soochow University, Southeast China: a cross-sectional study. J Pain Res. 2018;11:771.

18. Ibrahim NK, Alotaibi AK, Alhazmi AM, Alshehri RZ, Saimaldaher RN, Murad MA. Prevalence, predictors, and triggers of migraine headache among medical students and interns in king Abdulaziz University, Jeddah, Saudi Arabia. Pakistan J MedSci. 2017;33(2):270.

19. Zarea K, Rahmani M, Hassani F, Hakim A. Epidemiology and associated factors of migraine headache among Iranian medical students: a descriptive-analytical study. Clin Epidemiol Glob Health. 2018;6(3):109-14.

20. Shabi W, Akour A, Ageeli A, Najmi K, Hassan Y. Prevalence of migraine among medical students in Jazan University and its impact on their daily activities. Egyptian J Hospital Med. 2018;70(5):872-6.

21. Shahrakai MR, Mirshekari H, Ghanbari AT, Shahraki AR, Shahraki E. Prevalence of migraine among medical students in Zahedan Faculty of Medicine (southeast of Iran). Basic Clin Neurosci. 2011;2(2):20-5.

22. Adoukonou T, Tognon-Tchegnonsi F, Philomène $K$, Alabi A, Houinato D, Preux P-M. Prevalence of migraine among university students at Parakou, Benin: a cross-sectional study. World J Neurosci. 2014;2014:1-7.

23. Split W, Neuman W. Epidemiology of migraine among students from randomly selected secondary schools in Lodz. Headache: J Head Face Pain. 1999;39(7):494-501.

24. Kryst S, Scherl E. A population-based survey of the social and personal impact of headaches. Headache: J Head Face Pain. 1994;34(6):344-50.

25. Monteiro JP, Matos E, Calheiros J. Headaches in medical school students. Neuroepidemiology. 1994;13(3):103-7

26. Ogunyemi A. Prevalence of headache among Nigerian university students. Headache: J Head Face Pain. 1984;24(3):127-30.

27. Amayo E, Jowi J, Njeru E. Migraine headaches in a group of medica students at the Kenyatta National Hospital, Nairobi. East Afr Med J. 1996;73(9):594-7.
28. Murray CJ, Vos T, Lozano R, Naghavi M, Flaxman AD, Michaud C, et al. Disability-adjusted life years (DALYs) for 291 diseases and injuries in 21 regions, 1990-2010: a systematic analysis for the global burden of disease study 2010. Lancet. 2012;380(9859):2197-223.

29. Birru EM, Abay Z, Abdelwuhab M, Basazn A, Sirak B, Teni FS. Management of headache and associated factors among undergraduate medicine and health science students of University of Gondar, north West Ethiopia. J Headache Pain. 2016;17(1):56.

30. Zivadinov R, Willheim K, Sepic-Grahovac D, Jurjevic A, Bucuk M, Brnabic-Razmilic $\mathrm{O}$, et al. Migraine and tension-type headache in Croatia: a population-based survey of precipitating factors. Cephalalgia. 2003;23(5):336-43.

31. Vlajinac H, Šipetić S, Džoljić E, Maksimović J, Marinković J, Kostić V. Some lifestyle habits of female Belgrade university students with migraine and non-migraine primary headache. J Headache Pain. 2003;4(2):67.

32. Bessisso MS, Bener A, Elsaid MF, Al-Khalaf FA, Huzaima KA. The pattern of headache in school children in the State of Qatar. Saudi Med J. 2005:26(4):566

33. Tahir M, Mubashir R, Amin F. Prevalence \& management of headache \& its associated factors among female undergraduate pharmacy \& nonpharmacy student population of Lahore College for Women University, Lahore. Int J Sci Res Pub. 2017;7(424).

34. Goldberg LD. The cost of migraine and its treatment. Am J Manag Care. 2005;11(2 Suppl):S62-7

35. Lipton RB, Stewart WF, Diamond S, Diamond ML, Reed M. Prevalence and burden of migraine in the United States: data from the American migraine study II. Headache: J Head Face Pain. 2001:41(7):646-57.

36. Lipton RB, Bigal ME, Diamond M, Freitag F, Reed ML, Stewart WF. Migraine prevalence, disease burden, and the need for preventive therapy. Neurology. 2007;68(5):343-9.

37. Beghi E, Bussone G, D'Amico D, Cortelli P, Cevoli S, Manzoni GC, et al. Headache, anxiety and depressive disorders: the HADAS study. J Headache Pain. 2010;11(2):141-50.

38. Lipton RB, Dodick D, Sadovsky R, Kolodner K, Endicott J, Hettiarachchi J, et al. A self-administered screener for migraine in primary care: the ID migraine ${ }^{\text {TM }}$ validation study. Neurology. 2003;61(3):375-82.

39. Silberstein SD, Lipton RB, Sliwinski M. Classification of daily and near-daily headaches: field trial of revised IHS criteria. Neurology. 1996:47(4):871-5.

40. Cohen S, KamarckT, Mermelstein R. A global measure of perceived stress. J Health Soc Behav. 1983;24:385-96.

41. Nosikov A, Gudex C. Development of a common instrument for mental health. EUROHIS: Dev Common Instruments Health Surveys. 2003:57:35.

42. Dalgard OS, Dowrick C, Lehtinen V, Vazquez-Barquero JL, Casey P, Wilkinson $\mathrm{G}$, et al. Negative life events, social support and gender difference in depression. Soc Psychiatry Psychiatr Epidemiol. 2006;41(6):444-51.

43. Liao S, Shichong L, Xinyue C, Yi T, Shengrong S, Shan Z, et al. Quality analysis of Chinese popular scientific articles pertaining to novel coronavirus pneumonia; 2020

44. Scher A, Stewart W, Ricci J, Lipton RB. Factors associated with the onset and remission of chronic daily headache in a population-based study. Pain 2003:106(1-2):81-9.

\section{Publisher's Note}

Springer Nature remains neutral with regard to jurisdictional claims in published maps and institutional affiliations. 